\title{
TRADISI MAKKATTE' DITINJAU DARI \\ ASPEK GENDER DAN KESEHATAN REPRODUKSI PADA ETNIS BUGIS SULAWESI SELATAN
}

\author{
Subriah, Andi Syintha Ida \\ Jurusan Kebidanan, Poltekkes Kemenkes Makassar
}

\begin{abstract}
ABSTRAK
Khitan pada wanita sampai saat ini tetap menimbulkan kontroversi di Indonesia, masih banyak yang melakukannya secara ekstrim. Rumusan masalah penelitian adalah praktik khitan perempuan pada daerah etnis Bugis, Alasan apa sajakah yang mendorong masyarakat etnik Bugis melaksanakan Khitan perempuan, dan implikasi khitan perempuan terhadap kesehatan reproduksi. Jenis penelitian adalah kualitatif, yang bersifat natural setting berupa penekanan pada sifat kealamian sumber data yang menggambarkan hasil temuan di lapangan secara utuh menggunakan dasardasar teori yang ada, desain penelitian menggunakan grounded research dimana peneliti dapat mengembangkan semua pengetahuan dan teorinya setelah mengetahui permasalahan dan data dilapangan. jumlah informan inti tergantung dari tingkat kejenuhan informasi yang dibutuhkan atau menggunakan tehnik snowball dalam memperoleh data dan informasi. Jenis data yang digunakan adalah data primer dan data sekunder melalui kajian literatur, telaah dokumen, penelusuran internet serta penelusuran data lontara Bugis.Instrumen utama adalah penulis sendiri, didukung pedoman wawancara yang disusun dengan mengacu pada operasionalisme indikator fokus penelitian. Analisis data dilakukan dengan menggunakan pendekatan logika induktif, data disusun/digolongkan dalam pola, tema atau kategori yang diinterpretasikan dengan memberikan makna, menjelaskan pola, kategori dan mencari keterkaitannya antara satu dengan yang lainnya.. Hasil penelitian menunjukkan bahwa faktor penentu dilaksanakannya makatte adalah kepercayaan dalam konsep agama yang mewajibkan makkatte bagi anak perempuan dan budaya atau tradisi turun temurun dari nenek moyang orang Bugis, sedangkan implikasi khitan perempuan terhadap gender dan kesehatan reproduksi tidak menimbulkan efek negatif bila praktik makkatte dilakukan secara steril dan tanpa tindakan yang berlebihan ataupun melukai alat genitalia externa dan interna.
\end{abstract}

Kata Kunci : Makkatte', Gender, Kesehatan Reproduksi dan Tradisi Bugis Bone

\section{PENDAHULUAN}

Sustainable Development Goals (SDGs) merupakan komitmen besar Indonesia dan negara-negara sedunia untuk menciptakan sebuah dunia yang adil, sejahtera bagi rakyat dan bumi.Pada Goal 5 khususnya berbicara kesetaraan gender dan memberdayakan semua perempuan dan anak perempuan dimana pada Target ke-3 dituliskan menghapuskan segala semua praktikpraktik yang membahayakan, seperti perkawinan anak,dini dan paksa dan sunat pada perempuan (Kalibonso, 2015).

Riskesdas 2013 menyajikan data atau informasi tentang kebiasaan/perilaku Sunat pada anak perempuan umur 0-11 tahun, Secara nasional, persentase pernah diSunat pada anak perempuan umur 0-11 tahun sebesar 51,2 persen, dengan umur waktu diSunat tertinggi ketika umur $1-5$ bulan (72,4\%), namun ada juga yang diSunat ketika usia 1-4 tahun $(13,9 \%)$, dan 5-11 tahun (3,3\%). Menurut provinsi persentase tertinggi di Gorontalo $(83,7 \%)$ dan terendah di Nusa Tenggara Timur $(2,7 \%)$.

Komnas Anti Kekerasan Terhadap Perempuan mengatakan Sunat yang dilakukan terhadap wanita walaupun secara simbolis dengan menyayat atau mengoleskan kunyit tetap merupakan tindak kekerasan. Sedangkan sebelumnya pada tahun 2006 Kementerian Kesehatan telah mengeluarkan larangan Sunat perempuan yang dilakukan oleh petugas kesehatan. (Ida, 2005).

Wanita dan anak perempuan yang terberdaya adalah kunci mematahkan siklus diskriminasi dan kekerasan dan untuk mempromosikan dan melindungi hak asasi manusia, termasuk kesehatan seksual dan reproduksi dan hak-hak reproduksi. (Ida, 2005). Tujuan penelitian ini adalah untuk menemukan konsep tentang Sunat perempuan ditinjau dari aspek gender dan kesehatan reproduksi pada etnis Bugis Bone

\section{METODE}

\section{Desain, tempat dan waktu}

Desa Benteng Tellue Kecamatan Amali Kabupaten Bone dipilih sebagai lokasi penelitian dengan alasan tradisi makkatte" masih sangat melekat.

Jenis penelitian ini merupakan penelitian kualitatif, bersifat natural setting berupa penekanan pada sifat kealamian sumber data yang menggambarkan hasil temuan di lapangan secara utuh. (Sugiyono, 2009). 
Desain penelitian menggunakan grounded research untuk melakukan penarikan kesimpulan dipergunakan metode induktif yang didasarkan pada prosedur logika yang berawal dari preposisi-preposisi yang bersifat khusus sebagai hasil pengamatan dan berakhir pada suatu (Bungin, 2011).

\section{Jumlah dan cara pengambilan subjek}

Subjek dalam penelitian ini adalah masyarakat Etnis Bugis yang bermukim di Kabupaten Bone.

Analisis data dalam penelitian ini di lakukan secara terus menerus sejak awal sampai akhir penelitian dengan cara ini diharapkan suatu fenomena yang bersifat khusus dapat dideskripsikan pada suatu kesimpulan dalam konsep pengetahuan baru.

\section{HASIL}

Desa Benteng Tellue sebagai tempat penelitian merupakan salah satu Desa yang ada di Kecamatan Amali, yang masih sangat kental dengan budaya nenek moyang mereka. Informan dalam penelitian ini yaitu perempuan dewasa sebanyak 9 informan (telah tiba pada tingkat kejenuhan informasi), 1 informan kunci yaitu Sanro Pa'masi. (orang yang dituakan dan Dukun pada daerah tersebut), satu orang Bidan Desa. Penelitian ini melibatkan satu tokoh muda untuk mempermudah pintu masuk ke masyarakat dan sekaligus memperkecil kendala bahasa.

Wawancara dilakukan terhadap para ibu atau perempuan dewasa yang pernah mengalami sendiri atau melakukan sunat untuk anak-anak perempuan mereka. Wawancara mendalam ini berguna untuk mengeksplorasi nilai-nilai sosial kultural setempat yang diyakini dalam pelaksanaan sunat perempuan. Teknik ini digunakan sebagai bagian dari pendekatan etnografi untuk memahami eksistensi fenomena dan kedudukan sunat perempuan dalam kehidupan sehari-hari dari masyarakat Bugis.

Tradisi Makkatte' di Desa Benteng Tellue sudah dilaksanakan sejak dulu dan menjadi bagian dari kehidupan masyarakatnya. Saat anak berusia antara 4-7 tahun untuk perempuan, maka diadakan upacara peralihan yang disebut dengan upacara sunat atau Sunatan, bagi perempuan disebut makkatte". Acara ini juga disebut acara mappaseleng (pengislaman).

Berdasarkan hasil penelitian, ada 9 informan inti yang berhasil ditemukan dan menjadi subyek dalam penelitian ini, sebagaimana diuraikan berikut :

Praktik khitan pada perempuan atau Makkatte"pada etnis bugis bone

Berdasarkan wawancara dengan masyarakat yang dijadikan informan inti di peroleh informasi perihal praktik Makkatte' pada etnis bugis bone :

“........De' uiissengi arti tongeng tongenna makkatte...iaro bawang istilana makkatte ko makkunrai...."

Artinya :

Saya tidak mengetahui Arti makkatte' itu apa...yg saya tau istilah itu digunakan untuk perempuan yang mau dikhitan ( $\mathrm{Ny}$. $\mathrm{R}, 35$ thn, wawancara tanggal 24 Agustus 2016)

Wawancara mendalam tersebut diketahui bahwa pengertian makkatte' di kenal oleh informan hanya sebatas istilah bahwa perempuan yang di sunat atau di khitan disebut dengan makkatte'.

'....iya riolo di katte' tokka...sippada manengi idi to ugi'e makkatteki ko nadapini umuruta eppa taung..."

Artinya :

Saya dulu di khitan juga...semua orang bugis seperti itu pasti khitan kalau umurnya sudah 4 tahun.(Ny.DI,60 tahun, tanggal 24 Agustus 2016)

Dari wawancara di atas di dapatkan informasi bahwa khitan pada anak perempuan sangat perlu dikalangan suku bugis dan umumnya makkate ini dilakukan pada usia anak perempuan sekitar 4-7 tahun, Hal ini merupakan tradisi bagi suku bugis dan akan malu bila hal ini dilakukan terlambat atau tidak dilakukan.

“.....iya maneng to ugi' makkunraie pasti di kattei'....sippada to koe kampongnge....idi makkunraie dikatte manekki...aga nasabari..ka ko de' di kattekki.taniaki tu issleng....

Artinya :

Semua orang bugis perempuan pasti di khitan...seperti halnya di desa ini...semua perempuan di khitan sebab kalau tidak di khitan artinya bukan orang islam (Ny. 
Dr.50 tahun, wawancara tanggal 24 agustus 2016)

“....iya ro gunana makkate supaya mancaji islengi ana' - ana'e... ko karisteng de' to di kattei...idi meto bawang to isslangnge...di katteki tu'..."

Artinya :

Tujuan dari makkate atau khitan perempuan adalah supaya anak - anak sah menjadi Islam dan inilah perbedaan dari agama yang lain tidak perlu untuk di khitan.(Ny.B.50 tahun, wawancara tanggal 24 Agustus 2016)

Masyarakat bugis memahami tradisi makkatte' sebagai ritual budaya yang sangat penting untuk dilaksanakan pada anak perempuan. Anak perempuan yang belum melaksanakan makkatte' dianggap belum sah memeluk agama islam sehingga tradisi ini sangat penting untuk dilaksanakan, biasanya makkatte' ini dilakukan pada umur anak sekitar 4-7 tahun. Sanro biasanya melakukan tindakan pada daerah kemaluan anak perempuan yang di khitan kemudian dilanjutkan dengan tata cara adat makkatte' hal ini menunjukkan dilaksanakannya tradisi ini dengan baik dan apabila tradisi makkatte' ini terlambat untuk dilakukan ataupun tidak dilakukan maka si anak perempuan ataupun orangtuanya akan merasa malu.

Faktor penentu di laksanakannya khitan perempuan (Makkatte")

Beberapa faktor yang menjadi alasan informan melakukan Makkatte" yaitu :

“.....Idi to' ugi'e....memeng ipagaukengngi makkate'e asaba de' na' sah islenna tauwwe ko de'dikattei...."

Artinya :

Kami orang bugis memegang teguh tradisi khitan pada perempuan (makkatte) disebabkan pemahaman jika belum di khitan maka belum sah sebagai pemeluk agama islam (Ny.Ir,29 tahun, wawancara tanggal 24 Agustus 2016)

Dari beberapa petikan wawancara didapatkan alasan mengapa makkatte' dilakukan yaitu karena alasan tradisi dan alasan agama yang belum sempurna bila makkatte' tidak dilakukan.

",.....idi memeng to ugi'e tradisitta ko engka anak makkunrai pasti dikattei...sippada to anak uraneye ko nadapini umuruna pasti di sunnai...
Artinya :

Tradisi orang bugis kalau mempunyai anak perempuan pasti di khitan sama halnya dengan anak laki - laki kalau sudah cukup umurnya pasti di sunat.(Ny.J,45 tahun,wawancara tanggal 24 agustus 2016)

Dari wawancara yang di berikan informan di dapatkan informasi bahwa sepengetahuan informan tidak ada seorangpun yang mempunyai anak perempuan tidak mengkhitankan anaknya karena khitan pada anak perempuan wajib hukumnya seperti halnya anak laki - laki ini merupakan tradisi orang bugis atau kepercayaan mereka bahwa bila belum di khitan artinya belum sempurna keislamannya.

Informasi bahwa khitan pada perempuan tidak menggunakan biaya besar bahkan boleh di simpulkan sangat murah sehingga siapapun bisa melaksanakan khitan tersebut dan semua masyarakat Desa Benteng Tellue melaksanakan tradisi khitan ini dan tidak mengenal status pendidikan baik yang pendidikannya tinggi maupun yang tidak sekolah pasti melaksanakan tradisi makkatte' ini disebabkan kepercayaan yang mendasari bahwa khitan pada perempuan itu wajib hukumnya bagi umat islam dan tradisi turun temurun.

Pendapat perihal makkatte' menurut Suku Bugis ini tidak jauh berbeda dengan literature dan artikel yang banyak memuat tentang bagaimana hukum khitan bagi wanita menurut Islam, akan tetapi kajian tentang hukumnya masih ada silang pendapat perihal wajib atau sunnah hukumnya dalam islam, ini terjadi karena berbagai alasan dan sudut pandang yang berbeda dalam mengistimbath hukumnya.

Pendapat pertama mengatakan khitan hukumnya sunnah dan bukan wajib namun merupakan fithrah dan syiar islam, dalil yang digunakan adalah hadist Ibnu Abbas marfu kepada Rasulullah Shallahu Alaihi Wa Sallam, "Khitan itu sunnah buat laki - laki dan memuliakan buat wanita " (HR Ahmad dan Baihaqi) Selain itu mereka juga berdalil bahwa khitan itu sunnah bukan wajib karena di sebutkan dalam hadist bahwa khitan itu bagian dari fithrah dan di sejajarkan dengan istihdad ( mencukur bulu kemaluan ), mencukur 
kumis, memotong kuku dan mencabut bulu ketiak yang kesemuanya hukumnya sunnah karena itu khitanpun sunnah pula hukumnya.

Pendapat kedua mengatakan Khitan itu hukumnya wajib bukan sunnah, pendapat ini didukung oleh mazhab Syafi'l, mazhab Hanbali yang mengatakan bahwa hukum khitan itu wajib baik bagi laki - laki maupun bagi wanita, dan dalil yang digunakan adalah ayat Al Quran dan sunnah "Kemudian kami wahyukan kepadamu untuk mengikuti millah Ibrahim yang lurus" (QS. An-Nahl : 123),

Pendapat ketiga mengatakan wajib bagi laki - laki dan mulia bagi perempuan. Pendapat ini di pegang oleh ibnu Qudamah dalam Al Mughni, yaitu khitan itu wajib bagi laki - laki dan mulia bagi perempuan tapi tidak wajib. Diantara dalil tentang khitan bagi perempuan adalah sebuah hadist meski tidak sampai derajat shahih bahwa Rasulullah Shallahu alaihi wa Sallam pernah menyuruh seorang perempuan yang berprofesi sebagai pengkhitan anak perempuan. Rasulullah Shallahu Alaihi Wa Sallam bersabda "Sayatlah sedikit dan jangan bertlebihan, karena hal itu akan mencerahkan wajah dan menyenangkan suami"

Jadi untuk perempuan dianjurkan hanya memotong sedikit saja dan tidak sampai pada pangkalnya, khitan pada perempuan lebih kepada sifat pemulian semata, hadistnya pun tidak secara tegas memerintahkan untuk melakukannya, hanya mengakui adanya budaya seperti itu dan memberikan petunjuk tentang cara yang dianjurkan dalam mengkhitan perempuan, sehingga para ulamapun berpendapat bahwa khitan pada perempuan diserahkan pada budaya di setiap Negara.

Pendapat ketiga ini sejalan dengan yang diyakini oleh masyarakat bugis khususnya di Desa Benteng Tellue, Kec. Amali, Kab. Bone yang meyakini bahwa khitan pada perempuan atau makkatte" adalah kewajiban bagi umat Islam dan praktek khitan perempuan ini sudah membudaya pada masyarakat di Desa Benteng Tellue dan di jadikan tradisi turun temurun sehingga disetiap keluarga yang mempunyai anak perempuan praktik khitan ini pasti dilaksanakan.
Dikaji dalam aspek apapun masyarakat akan tetap melaksanakan praktik makkatte" ini, baik dari segi sosial ekonomi, agama maupun pendidikan tidak mempengaruhi untuk tidak di laksanankannya praktik makkate ini. Hal ini disebabkan kepercayaan yang sangat tinggi oleh masyarakat perihal kewajiban makkatte' bagi umat islam sehingga dapat di tarik suatu kesimpulan konsep bahwa :

" Faktor penentu dilaksanakannya makkate adalah konsep agama yang mewajibkan makkatte' bagi anak perempuan dan budaya atau tradisi turun temurun dari nenek moyang orang bugis.

Praktik Khitan Perempuan (makkatte") pada daerah etnis bugis Bone ditinjau dari gender dan implikasi terhadap kesehatan reproduksi.

"...... Sippada to iyya...umuru 5 taungnga kapang...makkateka...riolo mabaju bodo 7 lapiki ko makkateki...."

Artinya :

Sayapun demikian kira - kira umurku 5 tahun waktu itu saya di sunat...dulu kita memakai baju bodo 7 lapis kalau di sunat. (Ny.Ir,29 tahun, wawancara tanggal 25 agustus 2016)

“.....lya to'....indoku...neneku...idi maneng...de aga de' di katte....makkatte maneng, masiriki ko de' makkatte....sippada to urane disunnai tu nasaba wajib i'....."

Artinya :

Saya juga, mamaku, nenekku, kami semua tidak ada yang tidak di sunat,kami semua disunat, sebab malu kalau tidak disunat, seperti laki - laki yang juga disunnat sebab wajib hukumnya. (Ny.Jm,28 tahun, wawancara tanggal 25 agustus 2016).

Berdasarkan wawancara dengan masyarakat yang dijadikan informan inti di peroleh informasi tentang praktik khitan perempuan ( makkatte") pada etnis Bugis Bone di tinjau dari gender dan kesehatan reproduksi :

Dari wawancara dengan beberapa informan didapatkan informasi bahwa Semua informan inti pernah mengalami khiitan (makkatte'), ini disebabkan masih melekatnya kepercayaan masyarakat akan makna khitan tersebut yaitu kewajiban sebagai umat Islam sebagaimana yang dilakukan bagi laki-laki yang juga merupakan kebiasaan turun 
temurun. Anggota keluarga yang pernah dikhitan yaitu nenek, ibu, saudara perempuan, anak perempuan, alasan informan yaitu faktor tradisi juga psikologis dan sosial yaitu jika anak perempuan tidak dikhitan maka ia akan merasa malu dan takut menjadi bahan olok-olok temantemannya. Selain para orang tua juga merasa masih ada beban yang belum terpenuhi. Usia saat dikhitan yaitu 4-6 tahun, dimana itu sudah menjadi kebiasaan kalau khitan perempuan itu sebaiknya dan seharusnya pada usia tersebut.

Dari wawancara mendalam yang dilakukan pada informan inti di dapatkan informasi tentang tata cara khitan yang dilakukan adalah digores atau dikerok secara halus bagian Klitorisnya (cigi-cigi) dengan menggunakan pisau kecil, kadang ada yang berdarah dan ada yang tidak berdarah. Peralatan yang digunakan pada khitan perempuan (makkatte") dengan menggunakan pisau kecil yang dipakai dengan cara mengerok daerah klitoris (cigi-cigi)

Dari petikan wawancara diatas didapatkan informasi bahwa makkatte" tidak menyebabkkan rasa nyeri yang sangat kepada perempuan yang melaksanakannya, makkatte' juga tidak menimbulkan masalah pada kesehatan reproduksi wanita ini dimana tidak ada keluhan tentang kesehatan reproduksi pada perempuan yang telah melaksanakan makkatte' bahkan perempuan tersebut sudah mempunyai anak

Dari wawancara mendalam yang dilaksanakan pada informan, informasi yang di dapatkan adalah : Sebagian besar Informan tidak mempunyai keluhan yang dirasakan pasca khitan sehubungan dengan kesehatan reproduksinya bahkan sudah lupa dengan apa yang mereka rasakan saat di khitan, bahkan menurut informasi dari informan yang anaknya baru saja di khitan anaknya tersebut langsung bermain setelah pelaksanaan praktik makkatte', ketika informan di wawancara mengenai pemahaman informan tentang khitan sehubungan gender yang mengatakan sunat atau khitan pada perempuan merupakan suatu tindakan kekerasan pada perempuan, informan langsung mengungkapkan ketidak setujuan informan terhadap hal tersebut sebab bagi informan makkate adalah suatu kewajiban bagi umat islam untuk di laksanakan, informan juga membandingkan dengan sunat yang dilakukan oleh kaum laki - laki yang menurut informan sunat laki - laki lebih pantas dikatakan sebagai bentuk kekerasan sebab sunat laki - laki melalui proses pengguntingan alat kelamin.

Ini menarik untuk di kaji lebih lanjut sebab menurut SDGS gol 5 target 3 terdapat poin untuk menghapuskan semua praktik - praktik yang membahayakan pada perempuan dan salah satunya adalah praktik sunat perempuan karena sunat / khitan pada perempuan dianggap sebagai bentuk kekerasan pada perempuan. Begitupun pada saat informan di wawancara secara mendalam perihal kesehatan reproduksi yang tergangngu akibat makkate, beberapa informan memberikan penjelasan bahwa tidak pernah ada peristiwa yang harus di kwatirkan tsetelah pelaksanaan praktik makkatte' tersebut. Hal ini menunjukkan tidak ada efek samping yang dapat merisaukan masyarakat perihal praktik makkate ini sehingga masyarakat juga masih mempertahankan praktik ini bahkan sudah menjadi tradisi dan mengikat dalam kepercayaan agama yang mereka anut yaitu agama Islam. Hal ini sejalan dengan wawancara mendalam yang di lakukan kepada informan kunci yang dalam hal ini di wakilkan oleh Dukun / Sanro Desa Benteng Tellue yang memberikan informasi bahwa :

"......Hampir semua anak anak perempuan yang ada di Desa Benteng Tellue saya yang kattei, mereka tidak pergi ke bidan tapi ke saya, yang saya katte itu sekarang banyak yang sudah punya anak dan anaknya lagi saya yang katte juga, tidak pernah ada masalah karena makkatte' tersebut...itu saja kalau banyak bergerak atau menangis anaknya tidak sengaja tergores sedikit jadi berdarah tapi setelah itu tidak ada masalah....."

".....Alatku hanya pisau kecil ini (sambil memperlihatkan pisau lipat yang biasa digunakan)... biasanya kalau saya tau ada orang mau makkatte' pisau ini saya rendam dulu dengan air panas sebelum di 
gunakan bahkan saya masak sampai mendidih airnya....."

“.......biasana ku kerroji saja dibagiang atasna...nabilang orang cigi - cigina...trus dicera'i pakai ayam terus di doa-doakan supaya cepat ada jodo'na ini anak...begituji saja, tidak samami dulu bilang banyak sara - sara,na...sekarang sederhana saja..kecuali orang tuanya mau na bikingkang acara ada' baru di kasi pake baju bodo...

“....sepanjang sepengetahuan saya tidak adaji pernah ada masalah gara - gara makkate'...tidak pernahji ada kudengar...apalagi sakit keras karena makkatte' atau kenai kanker gara - gara makkatte' atau ada masalah di rahim sampai tidak ada anaknya...tidak adapi di desa ini yang sakit keras gara - gara makkatte'...karena dari dulu sayaji yang makkatte' di kampung ini jadi tidak ada masalah....."(Ny.SM, 26 tahun, wawancara tanggal 16 oktober 2016)

\section{PEMBAHASAN}

Dari informasi yang di berikan oleh informan kunci dapat ditarik suatu kesimpulan bahwa : Makkate yang dilakukan di Desa Benteng Tellue kabupaten Bone yang mana penduduknya mayoritas adalah etnis bugis adalah suatu praktik yang sudah lama dilakukan dan hampir semua masyarakat yang ada di Desa Benteng Tellue melakukan praktik makkate ini dan dari praktik makkatte' tersebut baik dari informan yang dijadikan subjek penelitian dan informan kunci memberikan jawaban yang tidak berbeda perihal gender dan kesehatan reproduksi perempuan

Praktik makkatte' menunjukkan tidak adanya efek samping terhadap kesehatan reproduksi perempuan yang ada di Desa Benteng Tellue. Hal ini mungkin di sebabkan karena praktik makkatte' yang dilakukan oleh Dukun / Sanro yang ada di Desa Benteng Tellu tidak sampai pada tindakan yang membahayakan alat reproduksi luar wanita dimana dalam praktiknya Dukun atau sanro yang ada di Desa Benteng Tellue hanya menggores atau mengeruk secara halus saja tanpa melukai bagian klitoris pada saat makkate'.
Tidak adanya efek samping pada alat reproduksi wanita pada praktik makkatte' di Desa Benteng Tellue juga di mungkinkan karena alat yang di gunakan untuk menggores atau mengeruk secara halus pada klitoris yaitu pisau kecil yang sebelumnya telah di bersihkan atau di sterilkan dengan cara merendamnya dalam air panas bahkan di masak terlebih dahulu sehingga meminimalkan kuman yang mungkin ada pada pisau kecil tersebut.

Dari pernyataan-pernyataan yang dikemukakan informan inti dan informan kunci maka secara perspektif kesehatan menggambarkan bahwa implikasi khitan perempuan terhadap gender dan kesehatan reproduksi perempuan yang melaksanakan praktik makkate' ini tidak menunjukkan adanya pengaruh yang signifikan dapat mengganggu kesehatan reproduksi perempuan yang melakukan praktik makkate' bila dilakukan secara steril dan tanpa tindakan yang berlebihan pada alat genitalia luar perempuan sehingga dapat ditegakkan suatu konsep bahwa :

"Praktik makkatte" yang dilakukan secara steril dan tanpa tindakan yang berlebihan ataupun tanpa melukai alat genitalia externa dan interna tidak menimbulkan implikasi terhadap gender dan kesehatan reproduksi seorang perempuan "

\section{KESIMPULAN}

Masyarakat bugis memahami tradisi makkatte' sebagai ritual budaya yang sangat penting untuk dilaksanakan pada anak perempuan. Anak perempuan yang belum melaksanakan makkatte' dianggap belum sah memeluk agama islam sehingga tradisi ini sangat penting untuk dilaksanakan, biasanya makkatte' ini dilakukan pada umur anak sekitar 4-7 tahun. Sanro biasanya melakukan tindakan pada daerah kemaluan anak perempuan yang di khitan kemudian dilanjutkan dengan tata cara adat makkatte' hal ini menunjukkan dilaksanakannya tradisi ini dengan baik dan apabila tradisi makkatte' ini terlambat untuk dilakukan ataupun tidak dilakukan maka si anak perempuan ataupun orangtuanya akan merasa malu. 
Faktor pencetus di laksanakannya praktik khitan perempuan (Makkatte") Agama merupaka suatu alasan yang sangat penting dan mendasar sehingga tetap di laksanakannya praktik makkatte', dikaji dalam aspek apapun masyarakat akan tetap melaksanakan praktik makkate ini, dari segi sosial, ekonomi maupun pendidikan tidak mempengaruhi untuk tidak di laksanankannya praktik makkatte" ini. Hal ini disebabkan kepercayaan yang sangat tinggi oleh masyarakat perihal kewajiban makkatte' bagi umat islam sehingga dapat di tarik suatu kesimpulan konsep bahwa : "Faktor penentu dilaksanakannya makkate adalah kepercayaan dalam konsep agama yang mewajibkan makkatte' bagi anak perempuan dan budaya atau tradisi turun temurun dari nenek moyang orang bugis. Implikasi khitan perempuan terhadap gender dan kesehatan reproduksi.

Implikasi khitan perempuan terhadap gender dan kesehatan reproduksi dapat dilihat dari ada tidaknya resiko yang di timbulkan dari praktik makkatte" tersebut dan dapat dilihat bahwa praktik makkatte" tidak menunjukkan adanya pengaruh yang signifikan dapat mengganggu kesehatan reproduksi perempuan yang melakukan praktik makkate' bila dilakukan secara steril dan tanpa tindakan yang berlebihan pada alat genitalia luar perempuan sehingga dapat ditegakkan suatu konsep bahwa : "Praktik makkatte" yang dilakukan secara steril dan tanpa tindakan yang berlebihan ataupun tanpa melukai alat genitalia externa dan interna tidak menimbulkan implikasi terhadap gender dan kesehatan reproduksi seorang perempuan ".

Praktik khitan atau sunat perempuan (makkatte") pada etnis bugis khususnya pada masyarakat Desa Benteng Tellue Kabupaten Bone yang masih terus dilaksanakan sampai saat ini karena alasan agama dan budaya dalam praktiknya tetap selalu memperhatikan unsur keselamatan dan kesehatan perempuan yang di sunat atau di khitan sehingga issu gender tentang kekerasan pada perempuan yang terdapat dalam praktik sunat / khitan perempuan yang dalam bahasa bugis di sebut dengan makkatte" tidak terjadi pada masyarakat bugis. Praktik Makkatte" yang dilaksanakan pada etnis bugis khususnya di Desa Benteng Tellue Kabupaten Bone dilaksanakan sepenuhnya oleh Sanro atau Dukun yang ada di desa tersebut dan tidak satupun praktik makkatte" ini dilakukan oleh petugas kesehatan khususnya Bidan, Agar dalam praktik makkatte" ke depan di harapkan sosialisasi dan dukungan dari petugas kesehatan yang bertanggung Jawab pada wilayah kerja Desa B.tellue untuk memberikan pelatihan tehknis kepada Sanro atau Dukun Agar tindakan serta alat yang digunakan pada proses makkatte' tidak menimbulkan masalah pada kesehatan reproduksi perempuan.

\section{DAFTAR PUSTAKA}

Burhan Bungin, 2011, Metodologi Penelitian Kualitatif Cetakan ke-8, PT Raja Grafindo, Jakarta

Departemen Kesehatan R.I. 2002. Modul Kesehatan Reproduksi Remaja.Jakarta

Departemen Kesehatan R.I. 2008. Profil Kesehatan Indonesia 2007.Jakarta

Djamaluddin Hatibu, 2015, http://www.rappang.com/2009/12/up acara-adat-Sunat.html , diakses tanggal 13 Januari 2016

Emi Nurjasmi, Ida Ruwaida Noor, Irwan M Hidayana, 2013, Perspektif gender dan HAM dalam asuhan kebidanan Komunitas, modul mahasiswi, Yayasan Pendidikan kesehatan Perempuan, Cetakan ke2, Jakarta

Hari Darmawan, 2013, http://ias3.blogspot.co.id/2013/12/makalahtentang-jenis-kelamin-dangender.html, diakses tanggal $19 \mathrm{Mei}$ 2016

Ifana

Safitri, http://ifanascout.blogspot.co.id/2015 /05/kesehatan-reproduksi-definisitujuan.html, diakses tanggal 12 februari 2016

Inna Noor Inayati, ketentuan tentang sunat Perempuan dikaitkan dengan azas gender dan non diskriminatif, Akademi Kebidanan Bandung Yayasan Ciara Putri. 
Kementerian Kesehatan, 2014, Pedoman

Pelayanan Kesehatan Reproduksi terpadu di Tingkat Pelayanan Kesehatan Dasar, Kementerian Kesehatan RI Direktorat Jenderal Bina Gizi dan KIA Direktorat Bina Kesehatan ibu

Manuaba, 2011, Buku Ajar Kesehatan Reproduksi untuk mahasiswa Bidan, EGC. Jakarta

Manuaba, 1998, Memahami Kesehatan Reproduksi Wanita. Arcan. Jakarta Notoatmojo, S. 2003, IImu Kesehatan masyarakat. Rineke Cipta. Jakarta

Prawirohardjo, S. 2014, IImu Kebidanan. Edisi keempat. YBS - SP. Jakarta

Rachmah Ida, 2005,

SunatBelengguAdatPerempuan Madura, Cetakan I, Inside Media, Yogjakarta.

Ridha

Sibolata, http://sibolataridha.blogspot.co.id/20 12/12/adat-suku-bugis.html diaksestanggal 13 Januari 2016

Rita Kalibonso dkk, Usulan Indiokator Pengarusutamaan gender dalam pembangunan berkelanjutan, Gerakan Perempuan Peduli Indonesia (GPPI), http://pkbi.or.id/wpcontent/uploads/2016/02/UsulanIndikator-PengarusutamaanGender-dalam-PembangunanBerkelanjutan-GPPI.pdf, diakses tanggal 19 Mei 2016

Sugiyono. 2009. Metode Penelitian Kuantitatif, Kualitatif dan $R \& D$. Alfabeta, Bandung

Wikipedia,

https://id.wikipedia.org/wiki/Gender \%28sosial\%29, diakses tgl 19 Mei 2016

Yani Widyastuti, 2011, Kesehatan Reproduksi, Cetakan IV, Fitramaya, Yogjakarta 